\title{
DNA Sequences as a Medium for Steganography Method of Codon Frequency with Character Frequency
}

\author{
Sadoon H. Abdullah \\ sadosb113@uomosul.edu.iq \\ College of Science \\ University of Mosul
}

Received on: 12/09/2011

\author{
Ahmed S. Nori \\ ahmed.s.nori@uomosul.edu.iq \\ College of Computer Science and Mathematics \\ University of Mosul
}

Accepted on: 02/11/2011

\begin{abstract}
The present study included an application of new method of steganography using DNA sequence as a medium for hiding. This method is considered as a secret cover for the secret message (text, image), avoid attention of unauthorized person in addition to be inextricable since it needs high effort, long time and well background in biology.

A Sequence of DNA has been synthesized chemically depending on the text secret message via using tables of symbols formed from English letter, numbers and special characters. Each symbol has been represented on codon and the symbols were arranged in the table in descending order depending on English letter frequency and codon frequency (Genes).

The DNA sequence has been synthesized by Korean Bioneer Company (sender), then the sequence has been read in university of fatih (the receiver) by DNA Sequence 3310 , the results revealed high similarity between sequence of the sender and receiver. And proved that the method is protected very well against analysis and stegoanalysis.

Keywords- Steganography, DNA Sequence, Genes, Steganalysis.

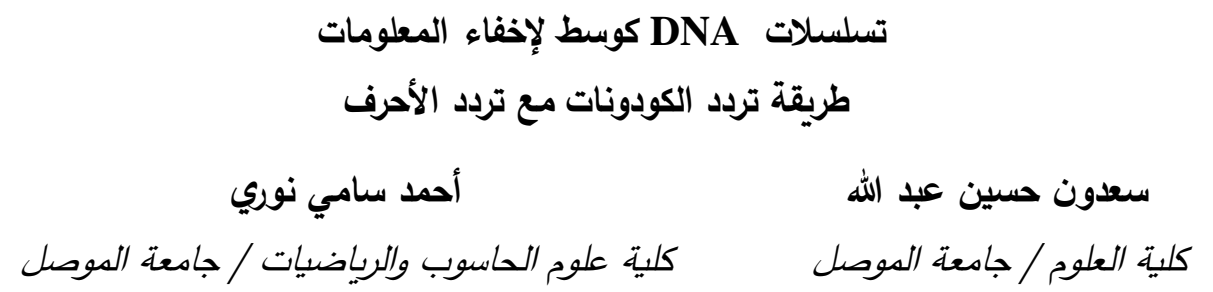

(الملخصن

يهدف البحث إلى تطبيق طريقة حديثة في الكتابة المغطاة Steganography وذلك باستخدام سلسلة

(Deoxyribonucleic Acid) DNA صورية) المخفية ويتجنب إثارة انتباه الأشخاص غير المخولين وصعوبة استرجاعها من قبلهم لأنها تحتاج إلى جهاء عالٍ ووقت طويل ومعرفة تامة بعلم الأحياء.

تم العمل على تصنيع سلسلة DNA كيميائيا بالاعتماد على الرسالة السرية النصية بالاستفادة من

جدول الأحرف الانكليزية وما يقابلها من الكودونات والمبنية بالاعتماد على تردد الأحرف الانكليزية وتردد الكودونات (لجينات معينة).
\end{abstract}


تم تصنيع سلسلة DNA في شركة Bioneer الكورية (المرسل) ثم تم نقل هذه السلسلة إلى جامعة الفاتح التركية (المستلم) ليتم قراءتها بجهاز DNA Sequencer 3310 وبالفعل كانت النتائج منطابقة في الجهتين، هذه

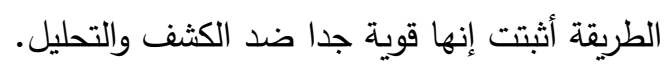
الكلمات المفتاحية: الكتابة المغطاة، سلسلة DNA، الجينات، التحليل.

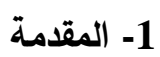

غالبا ما يحتاج مستخدموا الانترنت إلى خزن وإرسال أو استلام المعلومات السرية، والطريقة الأكثر استخداما لتنفيذ هذا الاحتياج هي بتحويل البيانات إلى شكل مختلف بحيث يمكن للأشخاص الذين يعرفون كيفية

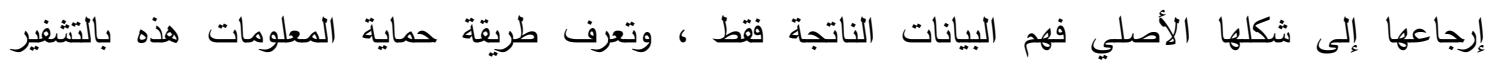
Encryption

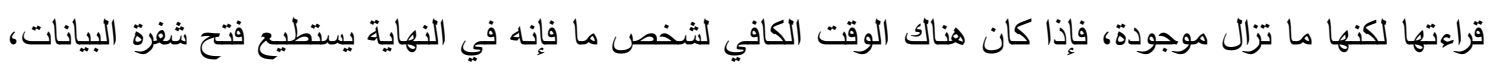
لذلك كان لابد من تطوير أمنية البيانات وإنشاء تقنيات جديدة، ومن هنا ظهر نظام التغطية Steganography.

ونظام التغطية هو فن إخفاء البيانات بصورة مبهمة في بيانات أخرى، والهدف منه بصورة عامة هو إخفاء

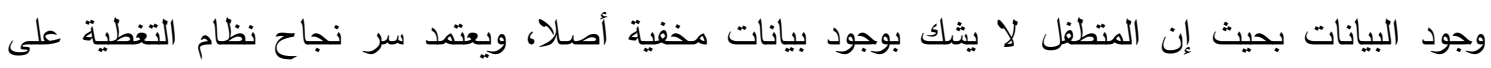

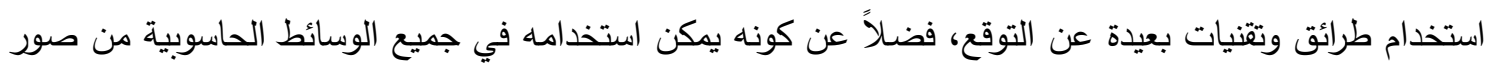
و نصوص و صوت و فيديو وحزم الثبكة، وبعكس التشفير الذي يعتمد على خوارزميات قياسية ومعروفة. [2]

2- 20 وصف الحامض النووي DA

يعد الحامض النووي DNA المادة الوراثية لخلايا حقيقية النواة Eukaryote وبدائية النواة Prokaryote ومعظم الفيروسات عدا بعض الفيروسات تتكون مادتها الوراثية من الحامض النووي RNA، يتكون الحامض النووي DNA من شريطين ملتفين بثكل حلزون مزدوج Double helix، كل شريط مكون من وحدات مكررة

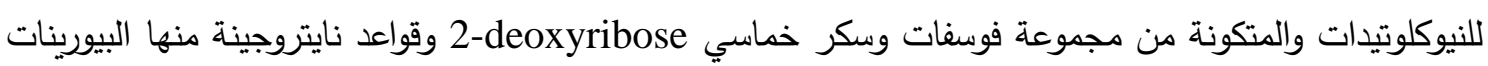

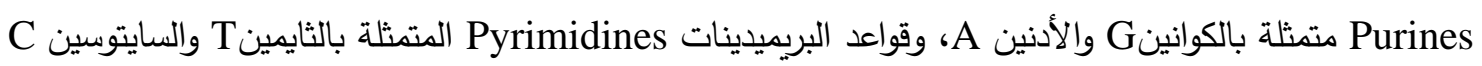

$$
\text { وتعد جزيئة سكر الرايبوز بمثابة العمود الفقري لشريطي }
$$

ترتبط النيوكلوتيدات فيما بينها بأواصر أسترية Phosphodiester bond، ويتم تثبيت الشريطين بأواصر

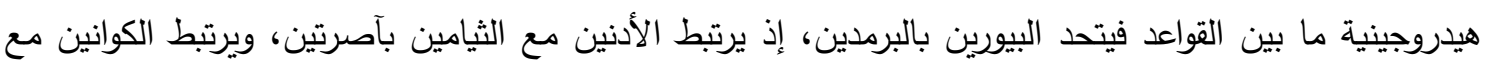

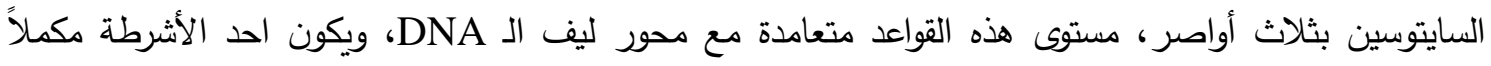
للآخر Complementary وعلى هذا الأساس وأثثاء التضاعف ينفصل الشريطان وكل شريط يعد قالباً Template، ويكون كل شريط بالنهاية مزدوجاً جديد[6،36 كما في الثكل(1) ، وفضلاً عن الأواصر الهيدروجينية

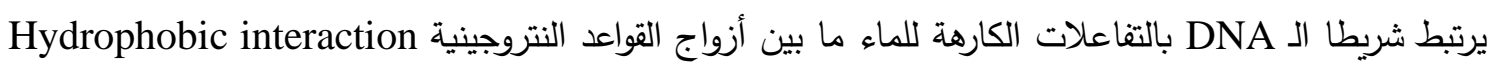
والتي تعمل على ثبات الحلزون المزدوج [4]. 
إن القطع ثلاثية النيوكلوتيد تدعى بالثفرة Codon والتي تكون مسؤولة عن إضافة حامض أميني لسلسلة

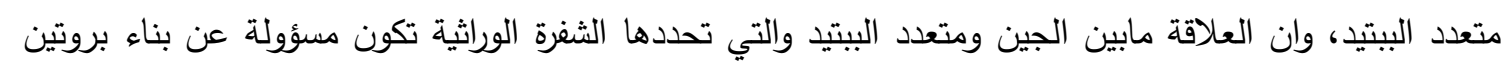
معين [7] معدد

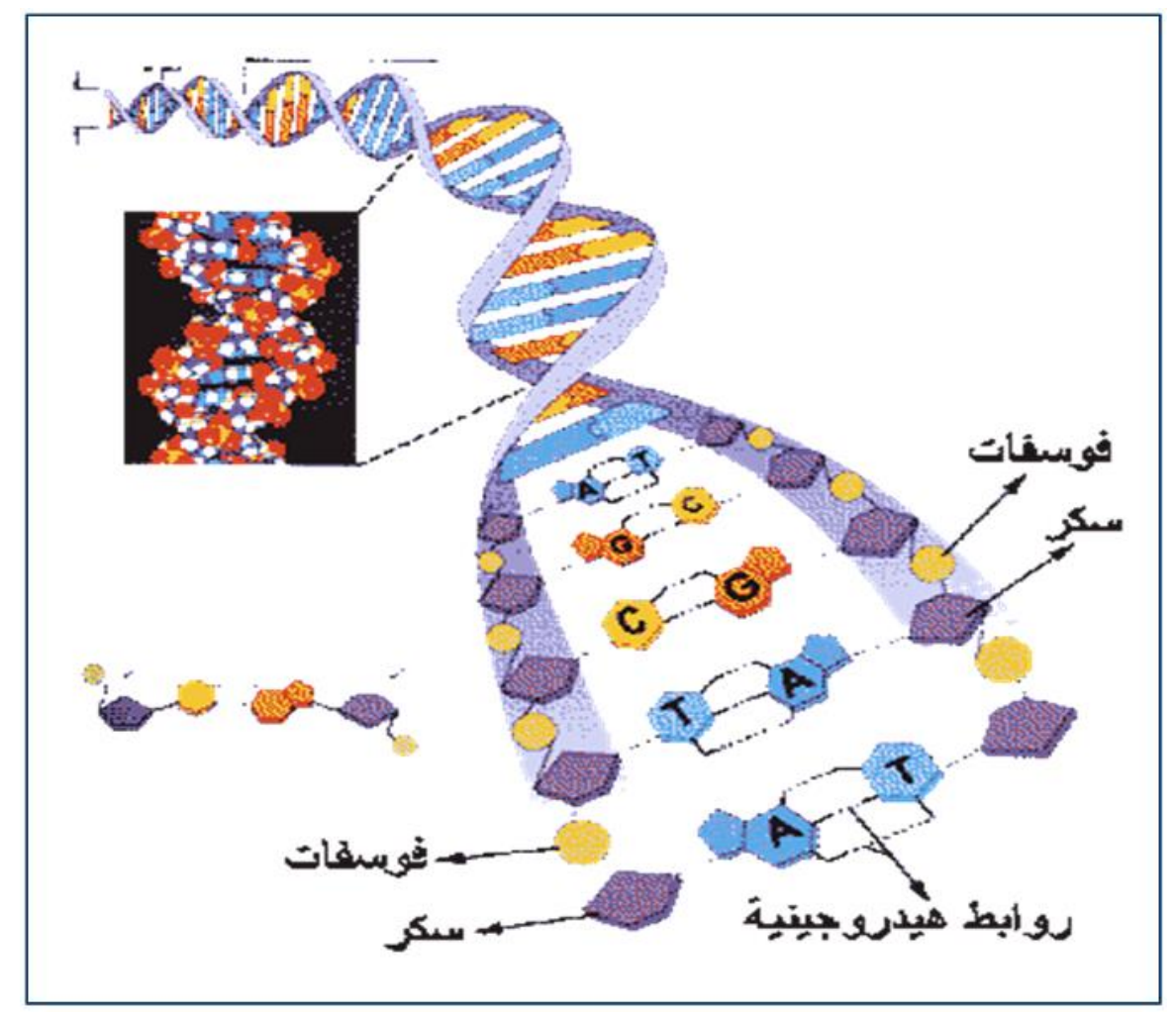

DNA الثكل (1). تركيب سلسلة

[8] (Genetic Analyzer 3310) DNA 1-2 جهاز قراءة سلسلة

ظهرت فكرة بناء أجهزة دقيقة تعمل على تقنية قراءة سلسلة DNA أو تحليل الجينات مع ظهور ثورة

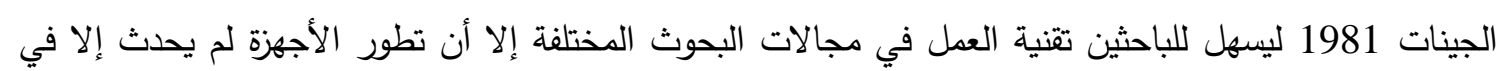

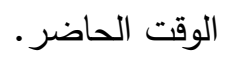
إن جهاز Genetic Analyzer 3310 الموضح في الثكل (2) من الأجهزة المتطورة حيث تقوم بعدة عمليات (تطبيقات) منها عملية قراءة قطع DNA وتركيب سلسلة DNA والتطفير وعملية الترحيل الكهربائي وعمليات أخرى. إن جهاز Genetic Analyzer 3310 سهل الاستخدام وسريع العمل وذو كلفة قليلة لإظهار النتائج وذو دقة عالية في النتائج، والجهاز لله القابلية على قراءة 864 قاعدة في سلسلة أحادية وقراءة 1000 قاعدة / زوج في سلسلة ثنائية. هنالك مجموعة من البرامج في الحاسوب المرتبطة مع الجهاز منها ما يستخدم لقراءة سلسلة DNA العنة وبرنامج لعملية الطفرة وغيرها.

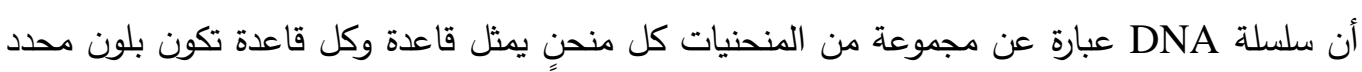

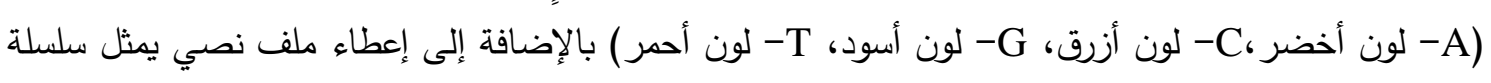




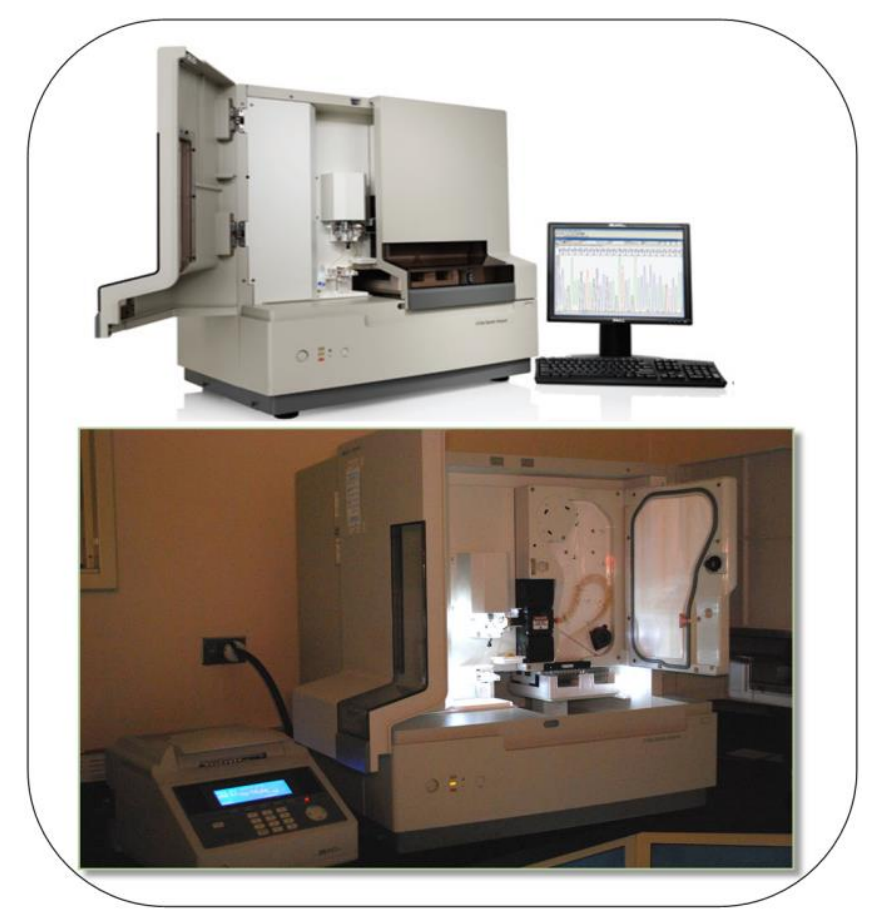

الثكل (2). جهاز قراءة سلسلة Genetic Analysis) DNA Sequencer 3310 DNA)

2-2 التفاعل التضاعفي لسلسلة الـ PCR)Polymerase Chain Reaction DNA

من التقنيات المهمة في البيولوجي الجزيئي، وتستخدم لزيادة كمية DNA PCR

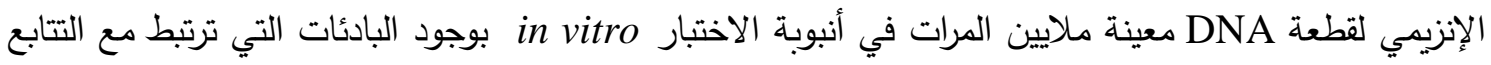
المكمل لها على الشريط الأصلي [10,9]. 3- طريقة تردد الكودونات مع تردد الأحرف.

من خصائص كل لغة وجود خاصية تردد أو نسبة تكرار كل حرف من الأحرف ضمن جملة معينة. وقد أثبتت الإحصائيات أن لكل لغة حية حرفاً له تكرار يختلف عن غيره، وعلى ذلك تم بناء جداول ومخططات كما هو في اللغة الانكليزية جدول (1) والثكل (3)[11].

جدول (1). نسبة تردد الأحرف في اللغة الانكليزية

\begin{tabular}{|c|c|c|c|c|c|}
\hline Letter & Frequency & Letter & Frequency & Letter & Frequency \\
\hline $\mathrm{E}$ & $12.702 \%$ & $\mathrm{R}$ & $5.987 \%$ & $\mathrm{P}$ & $1.929 \%$ \\
\hline $\mathrm{T}$ & $9.056 \%$ & $\mathrm{D}$ & $4.253 \%$ & $\mathrm{~B}$ & $1.492 \%$ \\
\hline $\mathrm{A}$ & $8.167 \%$ & $\mathrm{~L}$ & $4.025 \%$ & $\mathrm{~V}$ & $0.978 \%$ \\
\hline $\mathrm{o}$ & $7.507 \%$ & $\mathrm{C}$ & $2.782 \%$ & $\mathrm{~K}$ & $0.772 \%$ \\
\hline $\mathrm{i}$ & $6.966 \%$ & $\mathrm{U}$ & $2.758 \%$ & $\mathrm{~J}$ & $0.153 \%$ \\
\hline $\mathrm{n}$ & $6.749 \%$ & $\mathrm{M}$ & $2.406 \%$ & $\mathrm{X}$ & $0.150 \%$ \\
\hline Space & $6.378 \%$ & $\mathrm{~W}$ & $2.360 \%$ & $\mathrm{Q}$ & $0.095 \%$ \\
\hline $\mathrm{S}$ & $6.327 \%$ & $\mathrm{~F}$ & $2.228 \%$ & $\mathrm{Y}$ & $1.974 \%$ \\
\hline $\mathrm{H}$ & $6.094 \%$ & $\mathrm{G}$ & $2.015 \%$ & $\mathrm{Z}$ & $0.074 \%$ \\
\hline
\end{tabular}




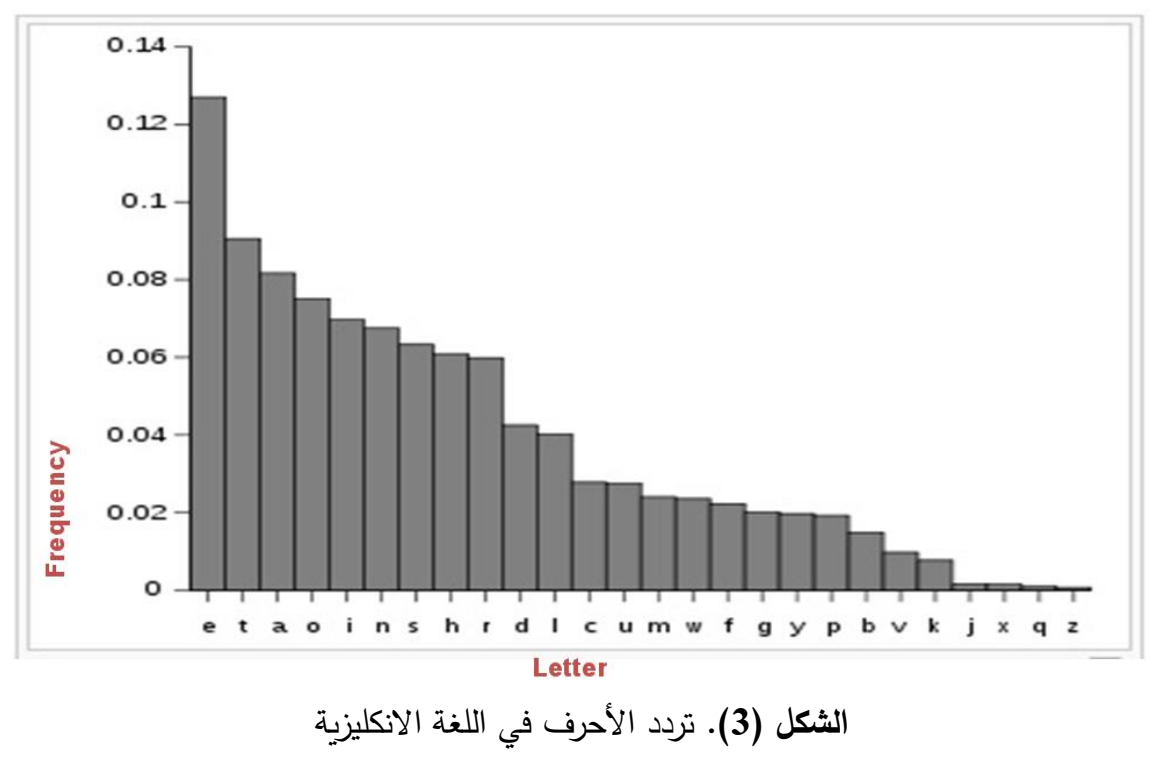

كذلك الحال بالنسبة لكل جين (بروتين) إذ تتواجد الحوامض الأمينية (الكودونات) التي تتكرر أكثر من غيرها في سلسلة الـ DNA. تمت الاستفادة من هذه الخاصية لغرض إعداد هذه الطريقة والمتمثلة بما يلي: حساب تكرار الأحرف حكات

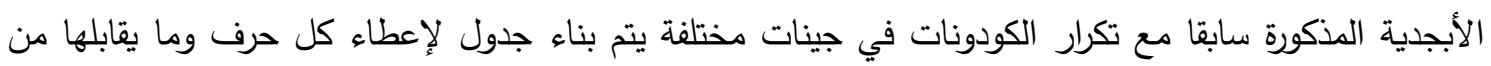
الكودونات والاستفادة منها في بناء سلسلة DNA اصطناعية والتي تمثل الرسالة النصية السرية. 1-3 عملية الإخفاء

وتتكون الخوارزمية من ثلاث مراحل رئيسة كما في الثكل (4) وهي: المرحلة الأولى: مرحلة تكوين الجدول المتضمن تكرار الأحرف الأبجدية والرموز والأرقام وما يقابلها من وناف الحامض الاميني ( الكودون) T2. المدخلات: سلاسل DNA من الموقع European Bioinformatics Institute) EBI) [10]، قدون) الجدول القياسي لتردد الأحرف.

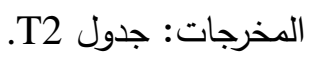
الخطوات:

1- إدخال سلسلة DNA لجينات مختلفة من موقع EBI. خلال هذه الطريقة يتم إدخال عدد من الجينات معروفة التسلسل من كائن بدائي النواة. مثال منعال $(\mathrm{G} 1, \mathrm{G} 2$

2- استخدام دالة لمعرفة تكرار كل كودون في كل سلسلة من سلاسل الجينات المختارة وترتيبها في جداول خاصة ( A1,A2 ..A10)، ثم إجراء عمليات إحصائية لكل الجداول السابقة ومنها يتم بناء جدول موحد 3- يتم الاستفادة من الجدول (T1) مـع الجدول (1) بحيث يتم مقابلة حقول الجدولين وإعطاء كل رمز في الجدول(1) ما يقابله من الكودون وحسب الترتيب وتكوين جدول (T2) . كما موضح في الثكل (5). 
المرحلة الثانية: مرحلة ترميز وتضمين الرسالة النصية وتتضمن هذه المرحلة:

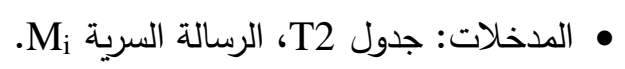

• المخرجات: سلسلة DNA اصطناعية Snew

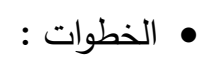

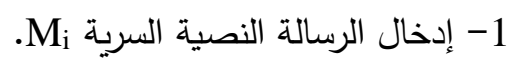

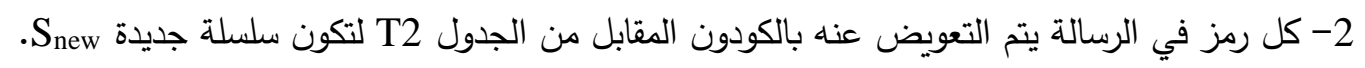

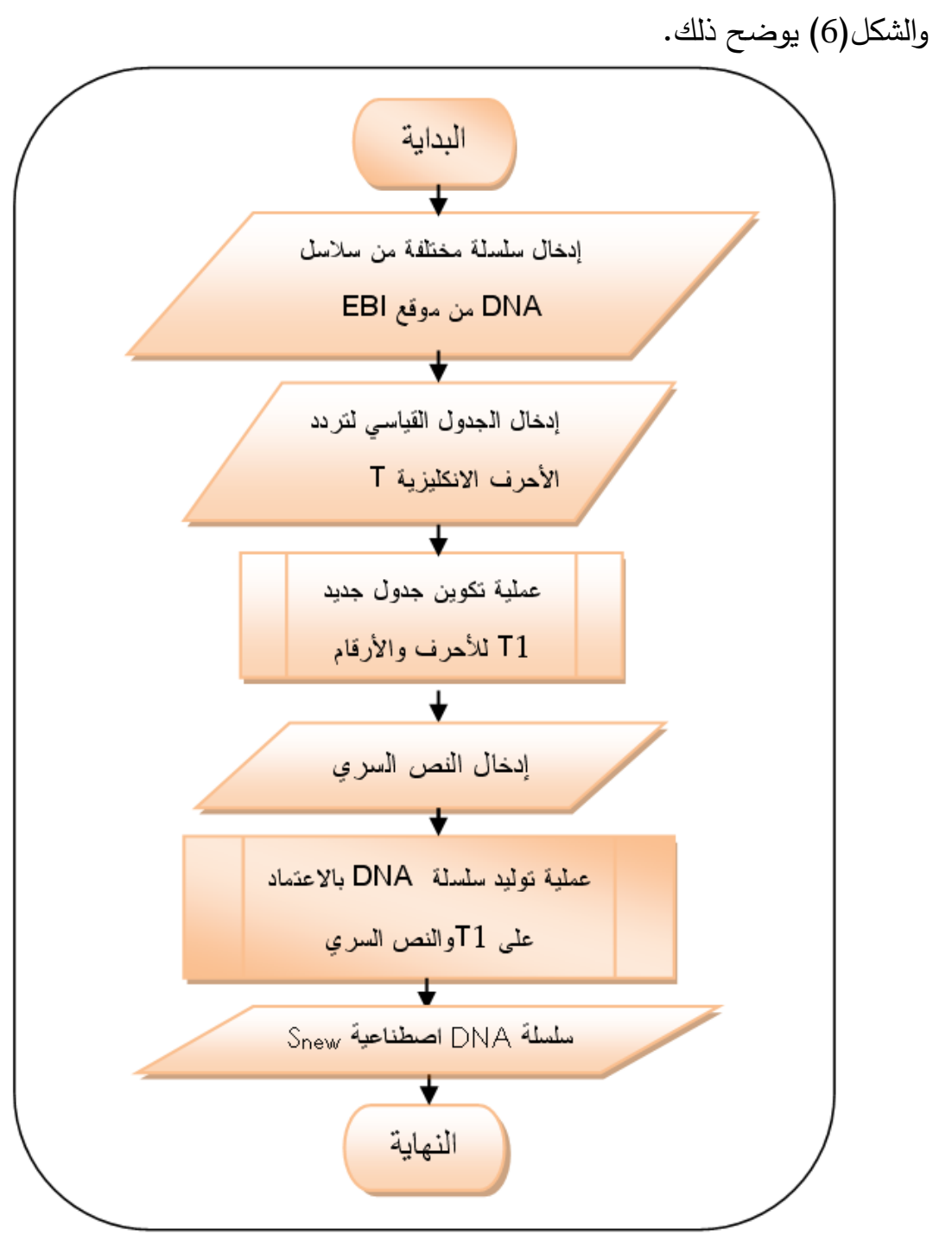

الثكل (4). المخطط العام لإخفاء الرسالة ضمن سلسلة DNA في الطريقة الثانية

المرحلة الثالثة: طرائق إرسال السلسلة السرية Special

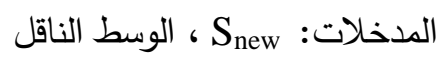

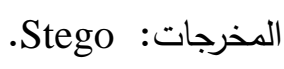

الخطوات:هنالك العديد من الوسائل لنقل السلسلة الناتجة Snew:

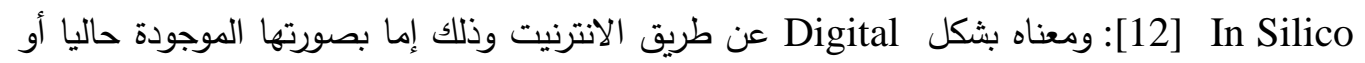
إخفائها في أحدى ملفات الوسائط المتعددة (Multimedia) لزيادة قوة الإخفاء. 
* [9 In Vitro : ومعناه بشكل طبيعي ( أنبوب اختبار) خارج الكائن الحي عن طريق وضعها ضمن وسط خاص.

تم إرسال سلسلة Snew DNA عن طريق تصنيعها كيميائيا (InVitro) ونقلها بثكل طبيعي ضمن وسط خاص

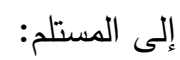

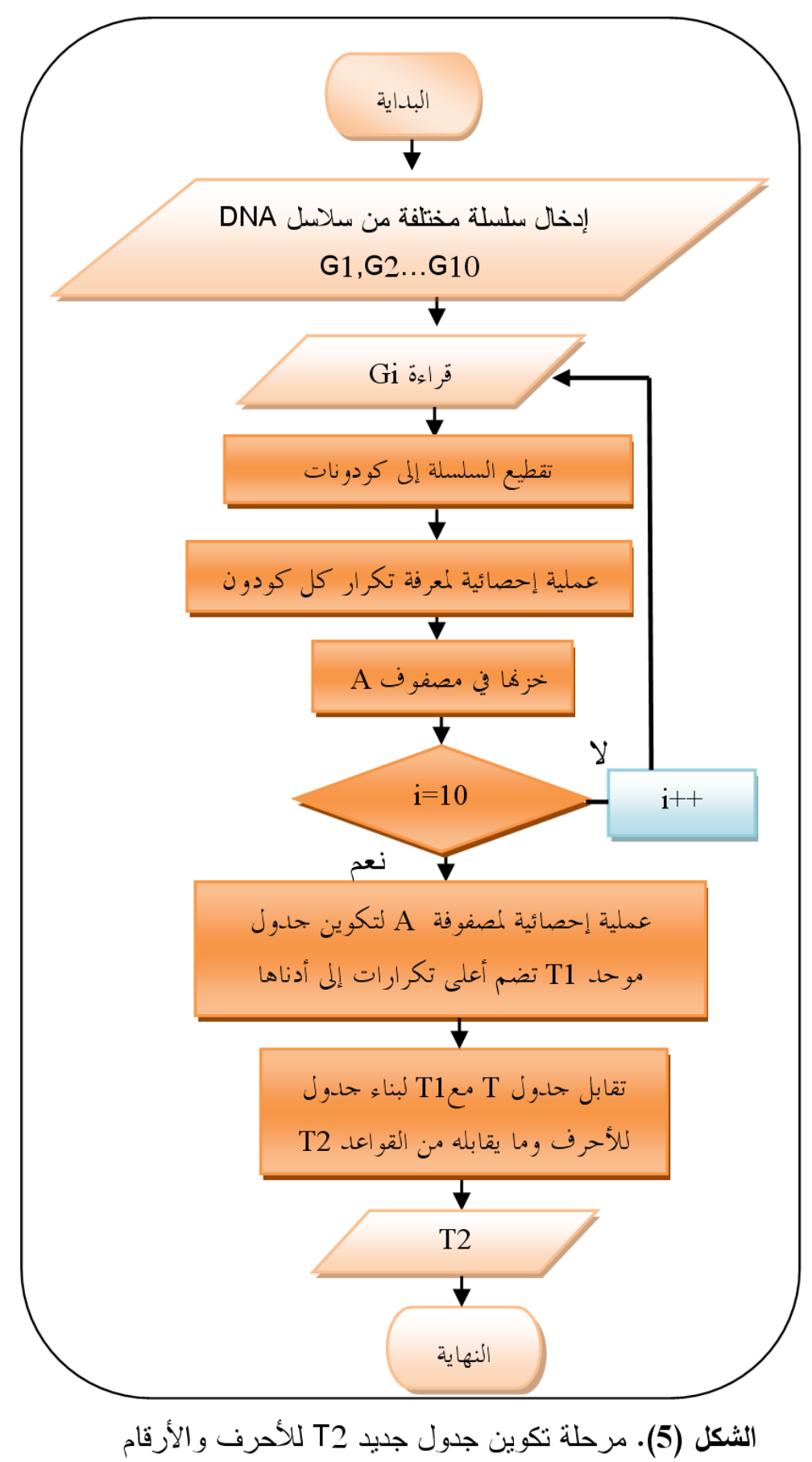




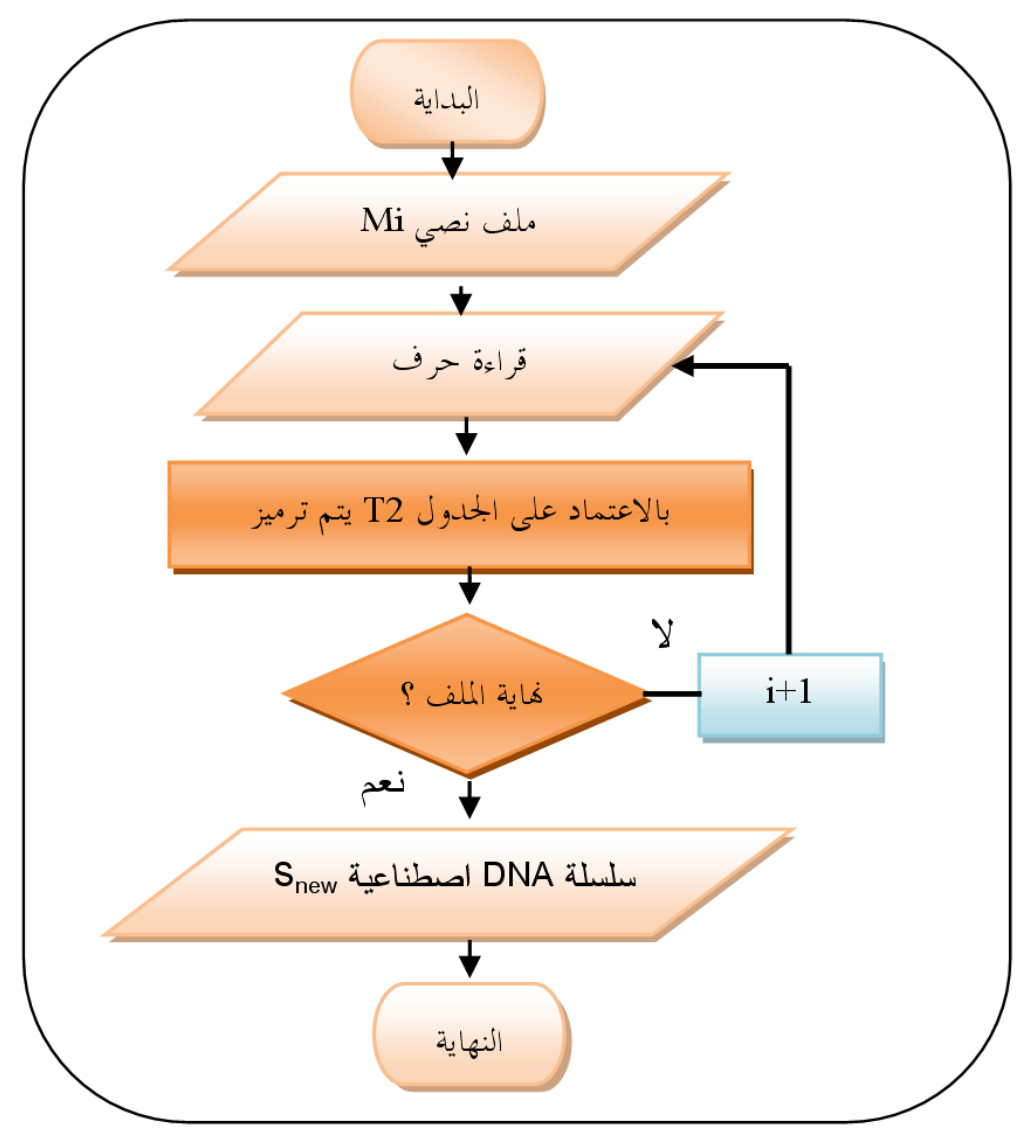

الثكل (6). عملية توليد سلسلة DNA بالاعتماد على T2 الرسالة السرية

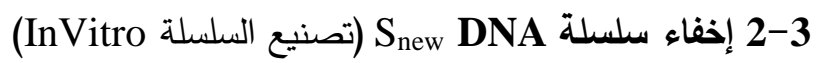
تم إرسال سلسلة Snew إلى دولة كوريا الجنوبية إذ تم تصنيعها من قبل شركة BIONEER [14] وفقا للرسالة السرية المرسلة والموضحة في المثال في الفقرة (3-5). تم استلام سلسلة DNA المصنعة من الشركة في أمبولة، والثكل(7) يوضح الامبولة الحاوية لسلسلة DNA المصنعة.

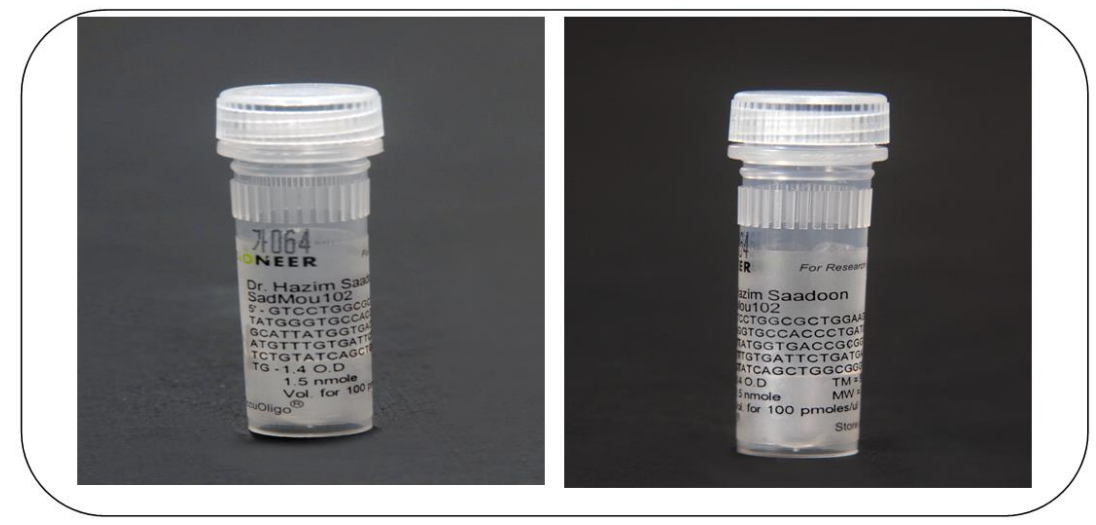

الثكل (7). الامبولة الحاوية لسلسلة DNA الحاملة للرسالة السرية

يبين الثكل (8) التقرير المفصل لسلسلة DNA المصنعة من شركة BIONEER والتي يوضح فيها الآتي: • الثركة المصنعة للسلسلة DNA. 


$$
\begin{aligned}
& \text { • الحجم الكلي للسلسلة والذي يساوي } 1.5 \text { نانو مول. } \\
& \text { • طول السلسلة } 102 \text { قاعدة حسب طول الرسالة السرية. }
\end{aligned}
$$

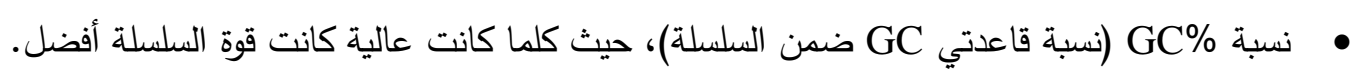
DNA من خلال هذه الثريحة يمكن التأكد من سلسلة PAGE Quality Core ) PAGE QC

المصنعة في جهاز الترحيل الكهربائي.

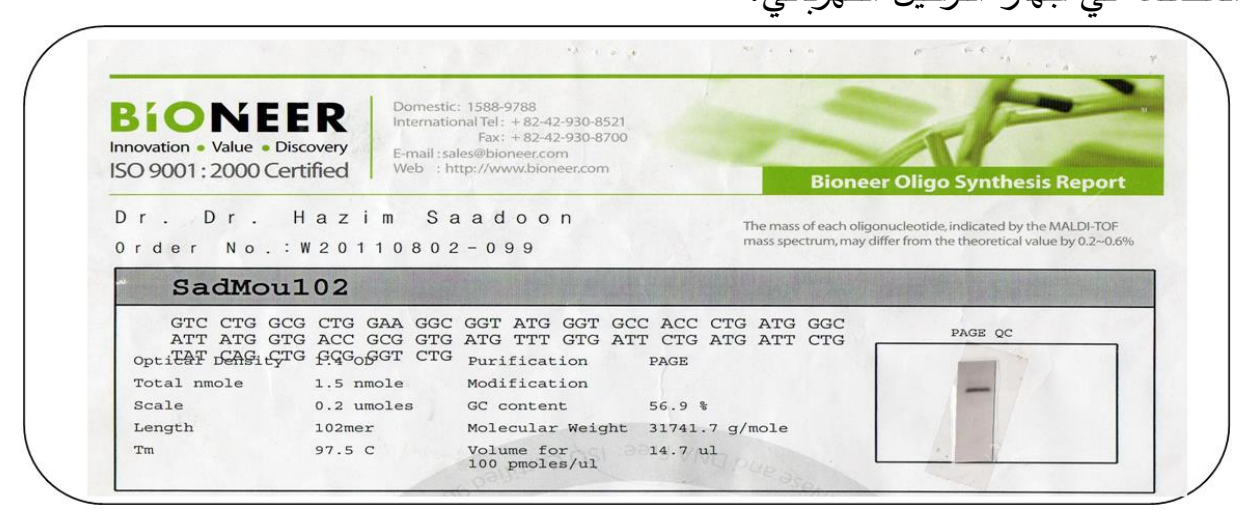

الثكل (8). تقرير شركة BIONEER

3-3 استرجاع سلسلة DNA المصنعة (قراءة سلسلة DNA)

بالرغم من قراءة سلسلة DNA من شركة BIONEER وتطابقها مع سلسلة الرسالة السرية في المثال

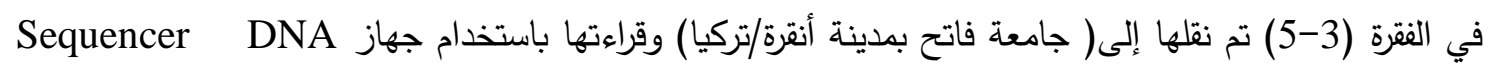

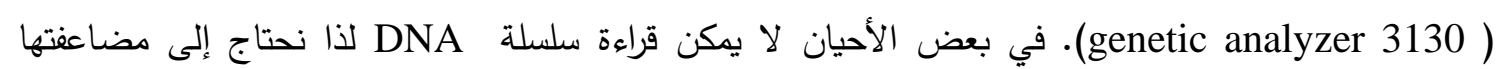

باستخدام تقنية PCR.

تم وضع السلسلة المصنعة ضمن الجهاز المذكور وتشغيل البرنامج الخاص ليتم قراءة السلسلة إذ تكون

النتيجة عبارة عن سلسلة من المنحنيات وبألوان مختلفة حسب قواعد سلسلة DNA كما في الثكل (9).

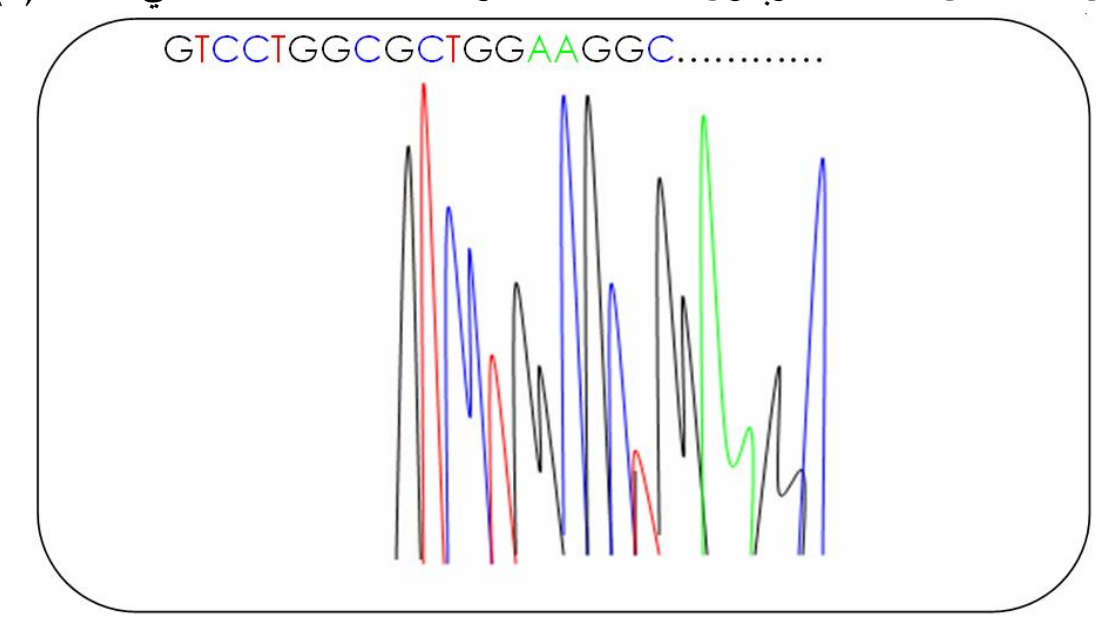

الشكل (9). نتيجة قراءة جهاز genetic analyzer 3130

4-3 استرجاع الرسالة السريـة

يقوم المستلم باسترجاع الرسالة السرية من سلسلة DNA المصنعة Sitro والتي تكون نتيجتها عبارة عن مخطط يمثل القواعد النتروجينية لسلسلة Stego DNA الحاملة للرسالة السرية. 
والثكل (10) يوضح المخطط العام لاسترجاع الرسالة السرية من سلسلة Sstego DNA والتي تمت بمرحلتين:

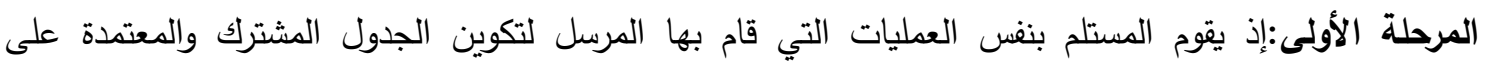

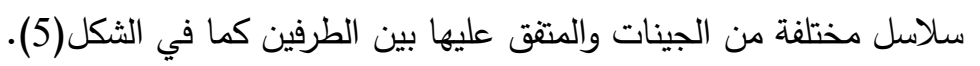

المرحلة الثانية: • • المدخلات: سلسلة S التي تحتوي الرسالة السرية.

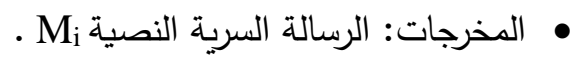

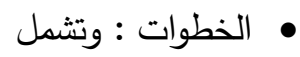

1- إدخال السلسلة الاصطناعية : 2- تقطيع السلسلة إلى كودونات.

3- قراءة كودون من الخطوة الثانية وحسب الجدول T1 يتم استرجاع الحرف المقابل وخزنها في مصفوفة.

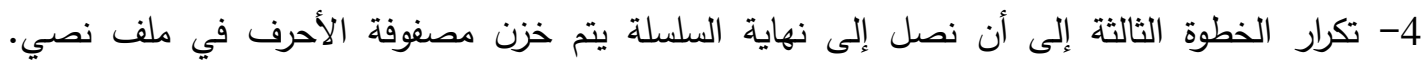

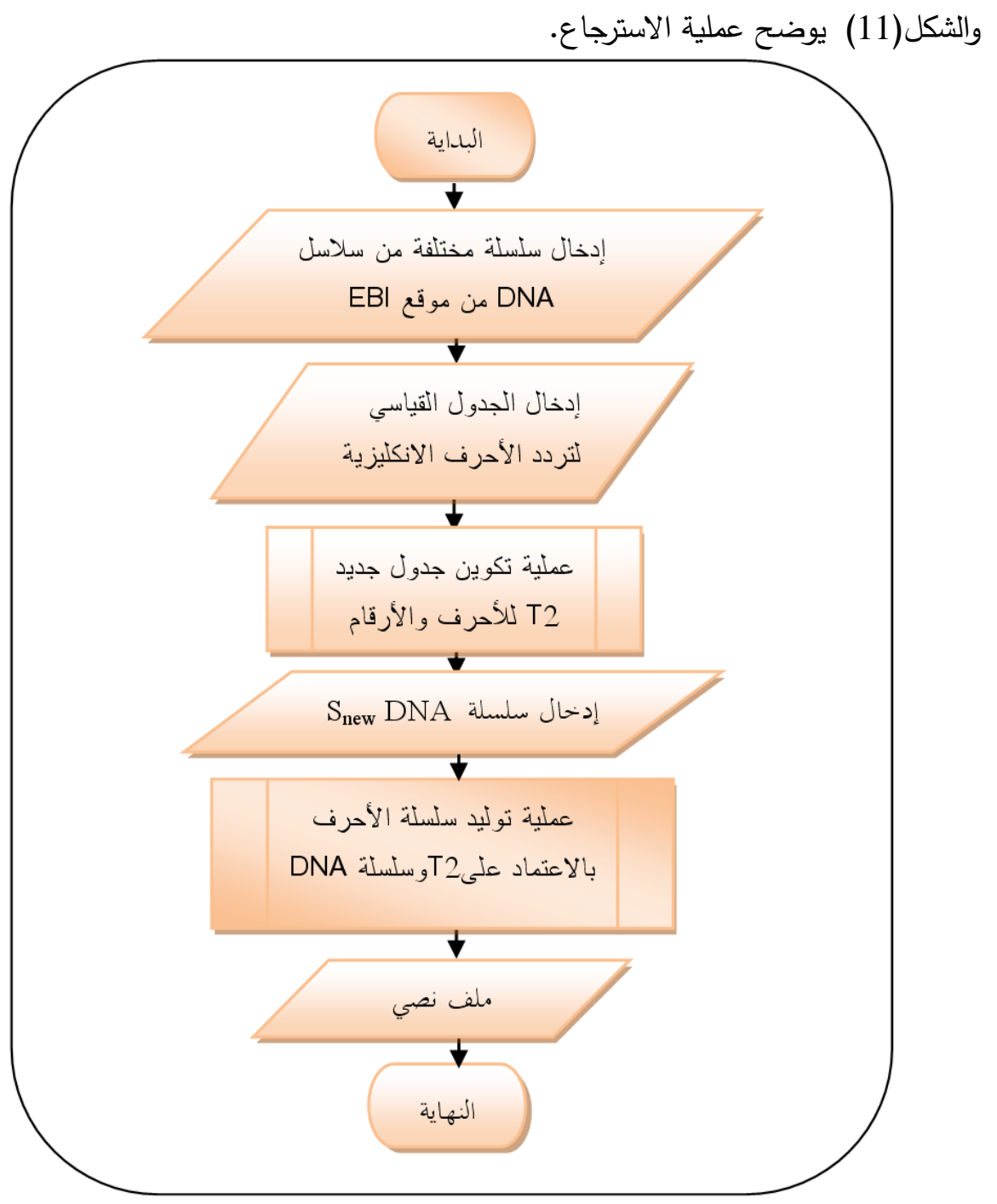

الثكل(10). المخطط العام لاسترجاع الرسالة ضمن سلسلة DNA 


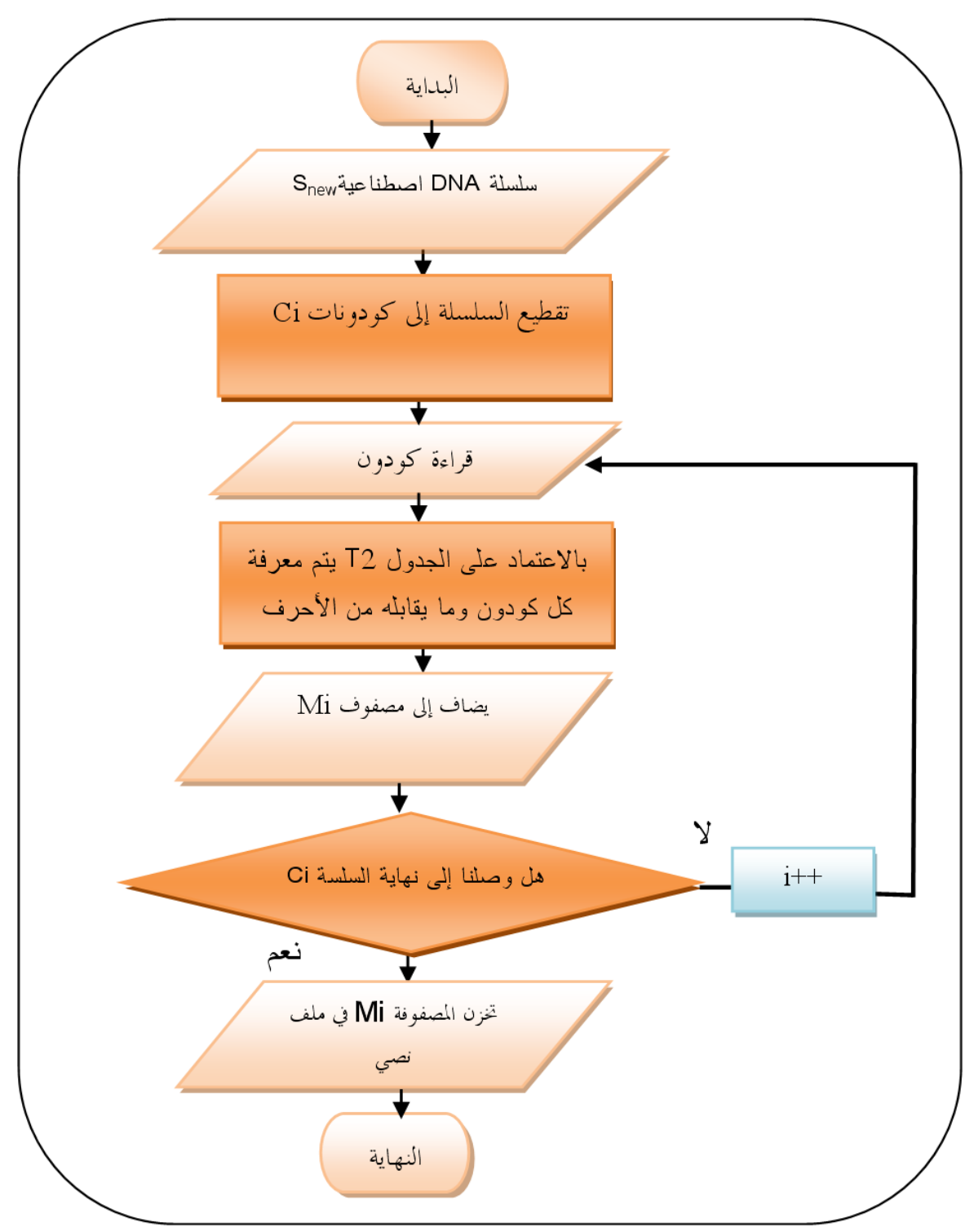

الثنكل (11). عملية توليد الرسالة السرية من سلسلة DNA وجدولT2

DNA 5-3 مثال توضيحي لإخفاء الرسالة السرية واسترجاعها من سلسلة

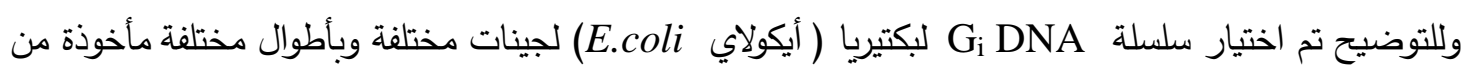
موقع EBI، وكانت نسبة تواجد كل حامض كما في الجدول (2). G1=ATGTGCGAAAAAAACGCCTATTTGCTCCTGTGGTTGGAAGGACCAT..... جدول (2). يبين نسبة تكرار كل كودون في سلاسل مختلفة

\begin{tabular}{|c|c|c|c|c|c|c|c|}
\hline Codon & Frequency & Codon & Frequency & Codon & Frequency & Codon & Frequency \\
\hline AAA & 52 & CAA & 36 & GAA & 150 & TAA & 4 \\
\hline AAC & 45 & CAC & 29 & GAC & 43 & TAC & 28 \\
\hline AAG & 47 & CAG & 60 & GAG & 51 & TAG & 3 \\
\hline AAT & 37 & CAT & 27 & GAT & 60 & TAT & 45 \\
\hline ACA & 22 & CCA & 24 & GCA & 65 & TCA & 24 \\
\hline ACC & 65 & CCC & 27 & GCC & 90 & TCC & 30 \\
\hline
\end{tabular}




\begin{tabular}{|c|c|c|c|c|c|c|c|}
\hline ACG & 59 & CCG & 45 & GCG & 98 & TCG & 37 \\
\hline ACT & 23 & CCT & 18 & GCT & 43 & TCT & 27 \\
\hline AGA & 7 & CGA & 17 & GGA & 20 & TGA & 14 \\
\hline AGC & 49 & CGC & 59 & GGC & 98 & TGC & 30 \\
\hline AGG & 12 & CGG & 25 & GGG & 28 & TGG & 44 \\
\hline AGT & 17 & CGT & 41 & GGT & 64 & TGT & 10 \\
\hline ATA & 12 & CTA & 10 & GTA & 23 & TTA & 41 \\
\hline ATC & 76 & CTC & 32 & GTC & 54 & TTC & 68 \\
\hline ATG & 85 & CTG & 160 & GTG & 103 & TTG & 46 \\
\hline ATT & 79 & CTT & 14 & GTT & 44 & TTT & 49 \\
\hline
\end{tabular}

(3) T1 T1 Tسترتيب الجدول (2) حسب الأعلى إلى الأدنى ينتج جدول

جدول (3). يبين ترتيب الكودونات حسب التكرار من الأعلى إلى الأدنى(T1)

\begin{tabular}{|c|c|c|c|c|c|c|c|}
\hline Codon & Frequency & Codon & Frequency & Codon & Frequency & Codon & Frequency \\
\hline CTG & 160 & CGC & 59 & TTA & 41 & GTA & 23 \\
\hline GAA & 150 & GTC & 54 & AAT & 37 & ACT & 23 \\
\hline GTG & 103 & AAA & 52 & TCG & 37 & ACA & 22 \\
\hline GCG & 98 & GAG & 51 & CAA & 36 & GGA & 20 \\
\hline GGC & 98 & TTT & 49 & CTC & 32 & CCT & 18 \\
\hline GCC & 90 & AGC & 49 & TCC & 30 & CGA & 17 \\
\hline ATG & 85 & AAG & 47 & TGC & 30 & AGT & 17 \\
\hline ATT & 79 & TTG & 46 & CAC & 29 & CTT & 14 \\
\hline ATC & 76 & CCG & 45 & GGG & 28 & TGA & 14 \\
\hline TTC & 68 & TAT & 45 & TAC & 28 & ATA & 12 \\
\hline ACC & 65 & AAC & 45 & CCC & 27 & AGG & 12 \\
\hline GCA & 65 & GTT & 44 & CAT & 27 & CTA & 10 \\
\hline GGT & 64 & TGG & 44 & TCT & 27 & TGT & 10 \\
\hline CAG & 60 & GAC & 43 & CGG & 25 & AGA & 7 \\
\hline GAT & 60 & GCT & 43 & CCA & 24 & TAA & 4 \\
\hline ACG & 59 & CGT & 41 & TCA & 24 & TAG & 3 \\
\hline
\end{tabular}

يتم الاستفادة من الجدول (3) مع الجدول (1) بحيث يتم مقابلة حقول الجدولين وإعطاء كل رمز في الجدول(1) ما يقابلها من الكودون وحسب الترتيب وتكوين جدول T2 (4).

جدول (4). ناتج تقابل كل كودون مع الحروف والأرقام والرموز

\begin{tabular}{|c|c|c|c|c|c|c|c|}
\hline Symbol & Codon & Symbol & Codon & Symbol & Codon & Symbol & Codon \\
\hline e & CTG & f & CGC & 5 & TTA & । & GTA \\
\hline t & GAA & g & GTC & 6 & AAT & । & ACT \\
\hline a & GTG & v & AAA & 7 & TCG & - & ACA \\
\hline o & GCC & p & GAG & 8 & CAA & $/$ & GGA \\
\hline i & GGC & b & TTT & 9 & CTC & $@$ & CCT \\
\hline n & GCG & v & AGC & $*$ & TCC & $!$ & CGA \\
\hline Space & ATG & k & AAG & $\&$ & TGC & $\wedge$ & AGT \\
\hline s & ATT & i & TTG & + & CAC & & CTT \\
\hline h & ATC & x & CCG & $>$ & GGG & $\vdots$ & TGA \\
\hline r & TTC & q & TAT & $<$ & TAC & A & ATA \\
\hline d & ACC & z & AAC & $=$ & CCC & $\vdots$ & AGG \\
\hline l & GCA & 0 & GTT & - & CAT & $\vdots$ & CTA \\
\hline c & GGT & 1 & TGG & $\#$ & TCT & $\sim$ & TGT \\
\hline u & CAG & 2 & GAC & $\%$ & CGG & l & AGA \\
\hline m & GAT & 3 & GCT & ( & CCA & I & TAA \\
\hline w & ACG & 4 & CGT & ) & TCA & $\$$ & TAG \\
\hline
\end{tabular}

ولتكن الرسالة المرسلة Mi باستخدام الجدول (4) يتم تصنيع سلسلة 


\section{$\mathrm{M}_{\mathrm{i}}=$ Genetic code is a DNA base sequence \\ $\mathrm{S}_{\text {new }}=$ GTCCTGGCGCTGGAAGGCGGTATG GGTGCCACCCTGATG \\ GGCATTATG GTGACCGCGGTGATG TTTGTGATTCTGATG \\ ATTCTGTATCAGCTGGCGGGTCTG}

يقوم المستلم أيضا بخطوات تكوين الجدولين ((3)،(4)) بعدها يتم استرجاع الرسالة السرية من سلسلة؛

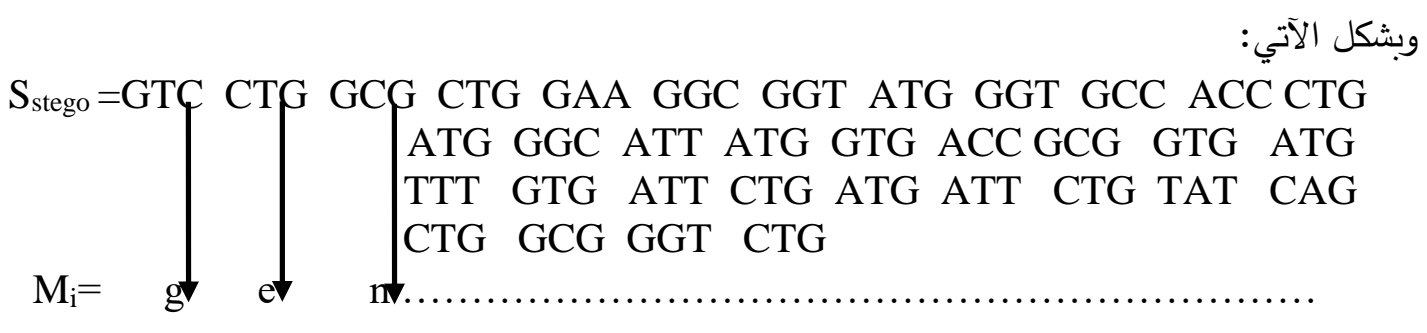

4

• في هذه الطريقة تم العمل على نقل سلسلة DNA وذلك بتصنيعها كيميائيا (InVitro) وهذه الطريقة من

الطرائق المعقدة والتي تحتاج إلى معرفة شاملة لكافة الأجهزة المختبرية منها Genetic Analyzer وغيرها. • في هذه الطريقة تم استغلال فكرة تردد الأحرف مع تردد الكودونات وهذا يعطي أهمية عالية لتثابه سلسلة المصنعة مع سلسلة DNA الحقيقية من ناحية الصفات وهذه لها فائدة عظيمة في حالة كثف سلسلة

.DNA

$$
\text { 1- من المميزات التي تم التطرق إليها ما يلي: }
$$

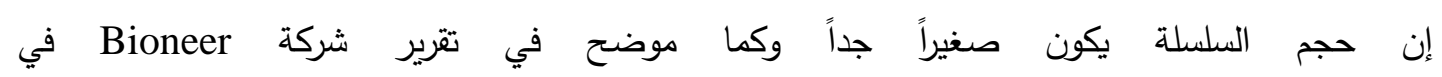
الثكل (7) إذ له فائدة كبيرة في سهولة الإخفاء والنقل إلى الطرف الثاني.

2- سلامة نقل سلسلة DNA المصنعة

تم نقل السلسلة إلى الطرف الثاني دون شك بوجود رسالة ضمن سلسلة DNA.

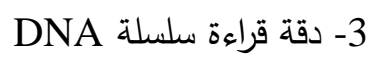

تم قراءة سلسلة DNA بشكل صحيح بدون وجود أي خطأ (BER=0) من قبل شركة Bioneer مناءة [14]، كما تم قراءتها في أجزة منطورة ( Genetic Analyzer 3130 بكلية الطب التابعة لجامعة فاتح/تركيا.

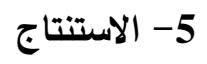

1- تعد سلسلة DNA وسطا جيداً جداً لإخفاء الرسالة السرية.

2- من البديهيات أن العمل مع سلسلة DNA يتطلب معرفة كاملة وخلفية نظرية في علم البيولوجي الجزيئي.

3- من عوامل القوة لهذه الطريقة هو ثبوت طول سلسلة الـ DNA وأثكالها وترتيبها قبل وبعد الإخفاء.

4- صُنعت سلسلة DNA مشابهة بالصفات لسلسلة DNA الحقيقية وذلك بالاستفادة من فكرة تردد الكودونات

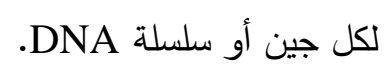

5- بالإمكان بناء سلسلة DNA صناعياً بالاعتماد على الرسالة السرية. 


$$
\begin{aligned}
& \text { المصادر } \\
& \text { الحمامي، عـلاء حسين والحمـامي، محمد عـلاء، 2008، "إخفاء المعلومـات: الكتابـة المخفيـة والعلامـة } \\
& \text { المائية "، إثراء للنشر والتوزيع، الثارقة. } \\
& \text { الجبوري، رشـا عـواد حسن، 2011، "تصـميم وتتفيذ نظـام هجين لتثففير وإخفاء الملف النصسي في } \\
& \text { بروتوكولات الصـوت عبر الانترنـت"، رسـالة ماجستير، قسم علوم الحاسبات، كليـة علـوم الحاسبات } \\
& \text { والرياضيات ، جامعة الموصل، العراق. }
\end{aligned}
$$

[3] Tamari, R.H., 1996, "principles of genetics", $S^{\text {th }}$ ed, Mc Graw -Hill companies, USA. http://www.rit.edu/ vxr8205/crypto2/cryptopaper.html.

[4] Dale, J. and Schants, M. V. 2002, "From genes to Genomes" JohnWiley \& sons , Inc . New York.

[5] Nelson, D.L. and cox, M.M. 2005, "Lehn: nger principles of Biochemistry", W. H. freeman and company, New York .

[6] Watson, J.D. and Crick, F.H., 1953, Molecular structure of nucleic acids: A structure for deoxyribose nucleic acid. Nature, 171: 737-738.

[7] Paolella, P., 1998, "Introduction to Molecular Biology". McGraw-Hill Companies, Inc., New York.

[8] http://www.appliedbiosystems.com, 2011, Applied Biosystems 3130 and 3130xl Genetic Analyzers, USA, 08/2006 publication 106 BR 1002. Sophisticate, dautomation, superiorperformance, streamlined setup, and 24-hour unattended operation.

العباسي، رغد رياض شفيق، 2008، "التغيرات الحيوية في خصائص الـ DNA لبكتريا

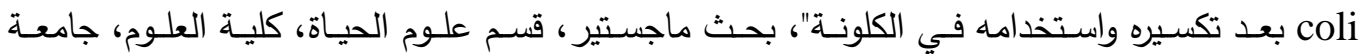

$$
\text { الموصل، العراق. }
$$

[10] Tamari, R.H., 1996, "principles of genetics", $S^{\text {th }}$ ed, Mc Graw -Hill companies, Inc., USA .

[11] http://www.Wikipedia.com, 2011, Frequency of Letters of the alphabet in English.

[12] http://www.ebi.ac.uk , 2011, European Bioinformatics Institute.

[13] Felix, B., (2006), "on the Embedding Capacity of DNA strands under substitution and Deletion Mutations", school of computer Science \& informatics, university college Dublin , Belfield -Compus, Dublin , Irelan.

[14] http://www.bioneer.com, Bioneer's, (2008) novel Nano-Technology, (Korea patent no.10-0850430, pct pending wo/072865). 